\title{
Annotations
}

\section{Who needs the clinical geneticist?}

General paediatricians face the increasing constraints of specialisation on their practice. Now next in line comes the clinical geneticist. Is he to be accepted as an ally and trusted colleague? Does his position, now firmly established on the medical scene, imply that only he is qualified to talk about the genetics of disease and counsel parents about the future? If he really believes that, what exactly is it that he can offer that is not easily found in the books of Harper, ${ }^{1}$ Emery and Rimoin, ${ }^{2}$ and McKusick? ${ }^{3}$

Fortunately, the calculation of recurrence risks is not the sole prerogative of the clinical geneticist, nor is it his only function. In practice, the clinical geneticist, like any other consulting colleague, will answer questions on the telephone, see children when asked, and talk to and give advice to parents on request. In some genetic clinics the geneticist sees children and parents alone, in others jointly with the paediatrician. When that happens the paediatrician remains in control and, having been witness to what has been said, is later in a better position to go over the ground, correcting misunderstandings and helping parents to reach decisions. In certain situations-to be made clear-the geneticist is likely to retain a distinct advantage over other clinicians, but the nature of that superiority will change as probabilities become fact and new techniques revolutionise our understanding of malformation and genetic disease.

The advantages that the geneticist has over the paediatrician are there to be exploited. The list includes a knowledge of genetic disease and its behaviour within families; a preparedness to examine such families as well as individuals; an understanding of biochemical and chromosomal genetics; a trained approach to the evaluation of malformation and dysmorphic signs; and a direct involvement with new laboratory techniques that will identify genetic disease. His position is central between the general practitioner, paediatrician, obstetrician, and other clinicians and investigators. $\mathrm{He}$ is supported by trained nursing staff who organise and attend clinics, maintain registers, visit, advise, and follow up families, and ensure that complex information discussed in clinics is understood. But with which families, and when, should he become involved? The answer depends on three factors: the needs of the parents, the nature of the disease, and the ability of the paediatrician to provide the answers.

\section{Malformation}

As isolated malformations are rarely the end result of a single mutant gene the risk of recurrence should always be low: it is, nevertheless, in most cases increased both for sibs and children. The most likely explanation is that polygenic or multifactorial influences are playing a part. For such isolated cases without obvious cause, the paediatrician will find that Harper's 'Practical genetic counselling" provides all the information he needs about recurrence risk once he has satisfied himself that there are no suspicious trends in the family. The risks are generally small and, if given early, are reassuring to parents, who are bound to be exposed to misleading, inaccurate, and unsolicited information in due course. Later on, parents may ask about prevention, as for neural tube defect, and the value, nature, and accuracy (as well as the risks) of tests that may be available in pregnancy. Oral or written advice from the geneticist should be sought at this stage.

When there is clustering of similar malformations in the family or sibship the risk of recurrence is higher. Sometimes this is because single mutant genes are operating as in Van der Woude's syndrome (cleft lip or palate with mucous cysts of lower lip, or both) or in the inherited form of encephalocoele (Meckel-Gruber syndrome), but there are less well defined situations for which risk figures are rarely available. Such families are better referred.

\section{Multiple malformations and the dysmorphic syndromes}

The geneticist also comes into his own when he is asked to define the future for the child with multiple malformations and determine whether the combination is fortuitous, familial, or the result of association (such as vertebral defects, imperforate anus, tracheo-oesophageal fistula, and radial and renal dysplasia) or sequence (as in Robin's syndrome) and so determine the chance of recurrence. Geneticists should be invited to see abnormal children in the newborn period as a matter of course if the diagnosis cannot be established immediately. Early answers 
can avoid the need for expensive investigations, but, even when a solution is not readily obtained, the sequence of these investigations can be logically determined. The geneticist's opinion is also of value to neonatal surgeons and cardiologists, who will want to know what the eventual outcome may be when advising parents and planning costly life saving and time consuming surgery.

In the last few years the delineation of rare malformation syndromes has achieved stupendous growth. Each new consultant clinical geneticist is now expected to have completed a formal training in the technique of visual dissection of these conditions, which is essential to achieve diagnosis. The interest is not effete for important questions about prognosis, and recurrence risks need to be answered and, in addition, firm labels, once applied, may help to lighten the burden of guilt that parents carry.

No one pretends that the diagnosis of the dysmorphic child is an easy challenge. When $\mathrm{Smith}^{4}$ has been perused and a chromosomal cause excluded one approach is to interrogate the computerised data base for the diagnosis of rare dysmorphic syndromes. ${ }^{5}$ In 1984 this contained information on about 700 syndromes accompanied by 1500 references gleaned from works published in the previous 15 years. By 1986 Baraitser and Winter had enlarged the 'London dysmorphology base' to include 1400 syndromes and 4500 references. (Baraitser M, Winter RM. Personal communication.) The authors have now added a facility that will allow new clearly defined 'unknowns', which have foiled panels of experts, to be included and later matched with others. Many genetic units already have copies of the dysmorphology base and have learned the tricks of interrogation. Nevertheless, even with this advance, a diagnosis may not be reached. This is particularly so when the child, retarded and with unusual facies, has no 'hard' signs, such as cleft palate or congenital heart disease, as signposts for the computer search. Frustrating as it still is, a careful assessment by the clinical geneticist remains the best approach to these problems.

\section{Single gene defects}

Paediatricians have always undertaken the responsibility of telling parents when their child's illness was the result of autosomal recessive inheritance, explaining the risks of recurrence and the consequence of the illness. Are they still competent to do this? In most cases the answer is 'yes', though in some cases they will ask either a colleague with special knowledge and experience of that disease to see the parents.
The immediate question for general paediatricians is whether organ or disease specialists, rather than geneticists, should be responsible for counselling many families with single gene disorders, especially those dealing with kidney, blood, and inborn errors of metabolism. In most instances the former will know more about the natural history of the disease and its behaviour within families than the geneticist, but he should be called in to advise on antenatal diagnosis and its coordination or to talk about the more difficult options, such as artificial insemination by donor. The same argument can be extended to include the nervous system, the ear, and the eye, but, in practice, counselling families with diseases that affect these systems is best provided by specialist and geneticist working together in the same clinic.

Whereas most doctors can explain the nature of the recurrence risks to parents of children with cystic fibrosis, calculations for risks further out in the family should be given with caution and preferably after checking the calculations with the geneticist. How many can calculate the risk of cystic fibrosis to the first cousin of an affected child (incidence of carriers in the population 1/20)? On a local course only six of 100 selected candidates for the part $1 \mathrm{MRCP}$ examination obtained the correct answer of $1 / 160$.

When the child's illness is a serious one the paediatrician does not hesitate to introduce information about its genetic basis and risks of recurrence. Explanations at this stage have to be presented clearly and simply but in such a way that parents will ask for more details later on. This is particularly important if a deleterious autosomal dominant or $\mathrm{X}$ linked recessive gene is responsible. The question then is whether the mutant gene lies hidden in the parent. When there is doubt the geneticist will examine or investigate the parents appropriately and, if necessary, look further into the family background. But what should the paediatrician do when he recognises an important disorder that is inherited as an autosomal dominant as part of a routine examination for some unrelated complaint, and where does the geneticist fit in there? Neurofibromatosis is a good example. In a proportion of children this is responsible for serious problems early in life, but most affected children are asymptomatic. The paediatrician remains the best judge of what should be said at the time, but should not the clinical geneticist be asked to talk about the disease, examine the parents, and describe how it may affect other members of the family differently at some later stage? The conundrum is how to balance the giving of unsolicited information without producing anxiety that then cannot be allayed. This difficulty is 
one that is ever present and to which the geneticist is more than sensitive.

\section{Investigation of families}

The difference between paediatricians and geneticists is that the former pride themselves with working with the family, the latter in investigating families. How many paediatricians are prepared to carry out the detailed examination of parents or have the facilities or time in their clinics to do so? There may be exceptions, such as in tuberous sclerosis or the examination of the urine in family members where Alport's syndrome is suspected. But who wants to arrange for the systematic collection of family bloods for chromosomal analysis and is then prepared to counsel the carriers, and how many know what subtle signs to seek in the rarer dominantly and $\mathrm{X}$ linked inherited disorders?

\section{Carrier detection}

Is the paediatrician competent to determine who is a carrier for a genetic disease? For diseases such as the haemoglobinopathies, where the investigation gives precise definition, there is no difficulty, but, when the interpretation of investigation is less exact and where pedigree analysis plays a part, as for linked disease, the problem must be referred. Bundey showed in 1978 how badly geneticists in the United Kingdom fared when asked to calculate the risks of families with Duchenne muscular dystrophy. ${ }^{6}$ They, at least, have now learned their lessons. DNA studies do now play a part in determining carrier state, but they are only of value to a small number of families. For the present, therefore, the calculation of odds remains a most useful method.

\section{Registers}

Should registers, dear to the heart of so many geneticists, be feared by paediatricians? Should their patients be included and, if so, for what benefit and at what cost? At present, registers of families with Duchenne muscular dystrophy are commonplace: they also exist for families with balanced chromosomal translocations and, lesser sophistication, for Huntington's chorea, polyposis coli, and familial polycystic kidney. The register is controlled by the geneticist and operated by nurse fieldworkers, whose job is to keep in touch with families, offer carrier detection tests, and, when appropriate, genetic counselling. Confidential records, whether on file or on disk, are kept under lock and key and only reached through the clinical geneticist. The keeping of such registers and the counselling of more distant family members are not part of the paediatrician's remit nor should he seek it unless he wishes to be the 'key person' when the genetic emergency-pregnancy-presents.

\section{DNA}

$\beta$ Thalassaemia, Duchenne muscular dystrophy, haemophilia $\mathrm{A}$, and cystic fibrosis are the main childhood diseases where DNA studies can provide a way of deciding accurately whether a fetus is affected. The current position with Duchenne muscular dystrophy, while regional laboratories are set up and funded, is that bloods from children and their parents should be channelled through the geneticist, who will arrange for storage, analysis, reports, and maintain a central DNA record. The last is essential for rapid recall at time of pregnancy, especially if chorion villus sampling examination is envisaged. In the cases of cystic fibrosis and $\beta$ thalassaemia the time will soon arrive when the records, interpretation, and advice will be best dealt with by the special clinic dealing with that particular disease, but $\mathrm{X}$ linked disease may well remain the exception because of the continued participation, testing, and counselling of female members of extended families through the register and the genetic fieldworkers.

\section{References}

I Harper PS. Practical genetic counselling. 2nd ed. Wright. 1984.

2 Emery AEH, Rimoin DL, eds. Principles and practice of medical genetics. Edinburgh: Churchill Livingstone. 1983.

${ }^{3}$ McKusick VA. Mendelian inheritance in man. 6th ed. Baltimore: The Johns Hopkins Press.

+ Smith DW. Recognisable patterns of human malformation. 3rd ed. Philadelphia: W B Saunders, 1982.

5 Winter RM, Baraitser M, Douglas JM. A computerised data base for the diagnosis of rare dysmorphic syndromes. $J$ Med Genet 1984;21:121-3

- Bundey S. Calculation of genetic risks in Duchenne muscular dystrophy by geneticists in the United Kingdom. J Med Genet 1978;15:249-53.

J INSLEY

Department of Clinical Genetics, Maternity Hospital, Birmingham B15 2TG 